\title{
Shifted dynamics of plankton communities in a restored lake: exploring the effects of climate change on phenology through four decades
}

\author{
S. Jannicke Moe ${ }^{1 *}$, Anders Hobæk ${ }^{2}$, Jonas Persson ${ }^{1}$, Birger Skjelbred $^{1}$, \\ Jarl Eivind Løvik ${ }^{3}$
}

\author{
${ }^{1}$ Norwegian Institute for Water Research (NIVA), 0349 Oslo, Norway \\ ${ }^{2}$ Norwegian Institute for Water Research (NIVA), 5006 Bergen, Norway \\ ${ }^{3}$ Norwegian Institute for Water Research (NIVA), 2312 Ottestad, Norway
}

\begin{abstract}
Lake surface temperatures have increased globally in recent decades. Climate change can affect lake biota directly via enhanced water temperatures, shorter ice cover duration and prolonged stratification, and indirectly via changes in species interactions. Changes in the seasonal dynamics of phytoplankton and zooplankton can further affect whole lake ecosystems. However, separating the effects of climate change from the more direct and dominating effects of nutrients is a challenge. Our aim was to explore the ecological effects of climate change while accounting for the effects of re-oligotrophication in Lake Mjøsa, the largest lake in Norway. While restoration measures since the 1970s have resulted in strongly reduced nutrient levels, the surface water temperature has increased by almost $0.4^{\circ} \mathrm{C}$ decade ${ }^{-1}$ during the same period. We analysed long-term trends and abrupt changes in environmental and biological time series as well as changes in the seasonal dynamics of individual plankton taxa. The general long-term trends in phenology were diverging for phytoplankton (later peaks) vs. zooplankton (earlier peaks). However, individual taxa of both phytoplankton and zooplankton displayed earlier peaks. Earlier peaks of the phytoplankton group Cryptophyceae can be explained by increased spring temperature or other climate-related changes. Earlier onset of population growth of certain zooplankton species (Limnocalanus macrurus and Holopedium gibberum) can also be explained by climatic change, either directly (earlier temperature increase) or more indirectly (earlier availability of Cryptophyceae as a food source). In the long run, climate-related changes in both phytoplankton and zooplankton phenology may have implications for the fish communities of this lake.
\end{abstract}

KEY WORDS: Climate change impacts $\cdot$ Phenology $\cdot$ Zooplankton community $\cdot$ Phytoplankton community $\cdot$ Lake temperature $\cdot$ Ice cover $\cdot$ Stratification $\cdot$ Trend analysis $\cdot$ Re-oligotrophication

\section{INTRODUCTION}

Lake ecosystems can be considered as sentinels of climate change (Adrian et al. 2009). Globally, lake summer surface temperatures have increased on average by $0.32^{\circ} \mathrm{C}$ decade ${ }^{-1}$ in recent decades (O'Reilly et al. 2015). In Lake Mjøsa, the largest lake in Norway, the surface water temperature has increased by almost $0.4^{\circ} \mathrm{C}$ decade $^{-1}$ during the last $40 \mathrm{yr}$ (Lyche

*Corresponding author: jmo@niva.no
Solheim et al. 2020). Besides the general warming trends, changes in precipitation and episodic events such as extreme heat have been observed and are forecast to increase further (IPCC 2014). Both warming and extreme events affect the biota of lakes directly via enhanced water temperatures that influence phenology (i.e. timing), biomass production and metabolic processes, and indirectly via a suite of effects (reviewed by Adrian et al. 2009, De Senerpont 
Domis et al. 2013). Among the most prominent climate-related changes are shortening of the ice cover duration and increased thermal stability, which reduces nutrient mixing from deep layers. Reported biological responses include reduced phytoplankton size, shifts in species composition and increased frequency and intensity of algal blooms, particularly of potentially harmful cyanobacteria. However, ecological responses to climate change in lakes also show site-specific patterns, influenced by local conditions such as community structure and species interactions (Flaim et al. 2016).

In boreal regions, reduction of ice cover and the subsequent extension of the growing season is a one of the most coherent response patterns in lakes (Blenckner et al. 2007, 2010, De Senerpont Domis et al. 2013). While there is strong evidence that climate warming promotes eutrophication of small lakes (Adrian et al. 2009), less is known about how climate affects plankton composition and food web interactions in large lakes (Shimoda et al. 2011). Since large lakes offer a wide range of ecosystem services to society, these water bodies are often subject to multiple pressures such as high nutrient loads, hydrological modifications and shifting of the food web balance by harvesting, in addition to climate change (Nõges et al. 2008). Management of large lakes, therefore, requires adequate consideration of climate change impacts in combination with local in-lake processes (Shimoda et al. 2011).

Alterations in temperature and other environmental cues may lead to phenological mismatches whereby the timing of critical events between interacting species becomes desynchronized, with potentially negative consequences (Cushing 1990, Smoliński \& Glazaczow 2019, Kharouba \& Wolkovich 2020). Differences in phenological responses to climate change among species can desynchronise ecological interactions and thereby affect ecosystem functioning (Thackeray et al. 2016). Both phytoplankton and fish have been identified as groups of lake biota with high sensitivity to climate change and eutrophication (Hering et al. 2010). Zooplankton is a key component of pelagic lake food webs, providing the link between phytoplankton and fish (Jeppesen et al. 2011). Zooplankton abundance peaks typically occur earlier in years with higher temperature (Adrian et al. 2006), and greater population instability can be anticipated with climate warming (De Senerpont Domis et al. 2013). Climate change may therefore affect whole lake ecosystems by decoupling the seasonal dynamics of phytoplankton and zooplankton (Winder et al. 2009) and may result in less food availability for fish that are dependent on zooplankton during their early development.

Aquatic ecosystems are typically affected by multiple stressors, which may have interactive effects on the biota (Nõges et al. 2016, Birk et al. 2020). Many lake ecosystems are dominated by eutrophication, resulting from excessive nutrient loads from agriculture and other types of land use (Jeppesen et al. 2010). Eutrophication and climate warming both promote algal growth and in particular cyanobacteria blooms (Paerl \& Huisman 2008). Therefore, separating the various effects of climate change from the more direct and dominating effects of nutrients is a challenge. A promising approach is to analyse long-term abundance data with high temporal and taxonomic resolution, which allows for the analysis of long-term trends in the seasonal dynamics of plankton communities (e.g. Pomati et al. 2012). However, multi-decadal data series suitable for such analyses are often the result of monitoring eutrophied lakes that have undergone restoration and subsequent re-oligotrophication, such as Lake Maggiore (Manca et al. 2007), Lake Zürich (Pomati et al. 2012) and Lake Geneva (Anneville et al. 2019). Potential effects of climate change (for example, increased phytoplankton biomass) may therefore be counteracted by reduced nutrient concentrations (Jeppesen et al. 2005). Disentangling the potential ecological effects of increased temperature from the strong effects of reduced nutrient pressure is therefore also a challenge, as reported for Lake Mjøsa (Hobæk et al. 2012). Earlier analyses of the plankton communities in Lake Mjøsa have suggested that the annual peak of the total phytoplankton biomass has shifted to a later timing during the growing season, while the peak of the total zooplankton biomass seems to have shifted to an earlier timing (Moe et al. 2014). However, trends in plankton phenology observed in restored lakes are not necessarily representative of lakes in general, and documented changes in phenology should not be attributed to climate change without any mechanistic explanation (Vadadi-Fülöp et al. 2012, Vadadi-Fülöp \& Hufnagel 2014). Moreover, such explanations must consider both bottom-up factors (climate and resources) and top-down factors (grazing or predation) (Anneville et al. 2019).

The purpose of this study, therefore, was to explore the ecological responses of plankton communities to environmental trends related to climate change in Lake Mjøsa, while accounting for the influence of reoligotrophication following the lake restoration. Our approach was to analyse the $40 \mathrm{yr}$ time series of environmental and biological monitoring data from Lake Mjøsa to investigate (1) long-term trends and abrupt 
changes in the environmental and biological time series, (2) changes in species composition of the phytoplankton and zooplankton communities, (3) changes in the seasonal dynamics of individual plankton taxa and (4) relationships between environmental variables and the phenology of individual plankton taxa. We aimed to explain the observed trends in phenology by accounting for both bottom-up and top-down controlling factors, by combining explorative statistical methods and local expert knowledge of the ecosystem.

\section{MATERIALS AND METHODS}

\subsection{Study site}

Lake Mjøsa is Norway's largest lake (Fig. 1), with a surface area of $362 \mathrm{~km}^{2}$ and a mean depth of $155 \mathrm{~m}$. The main tributary drains mountainous regions, and during snow melt, this river feeds Lake Mjøsa with cool water into early summer. Lowland areas around the central part of the lake constitute agricultural districts. The total population in the catchment is about

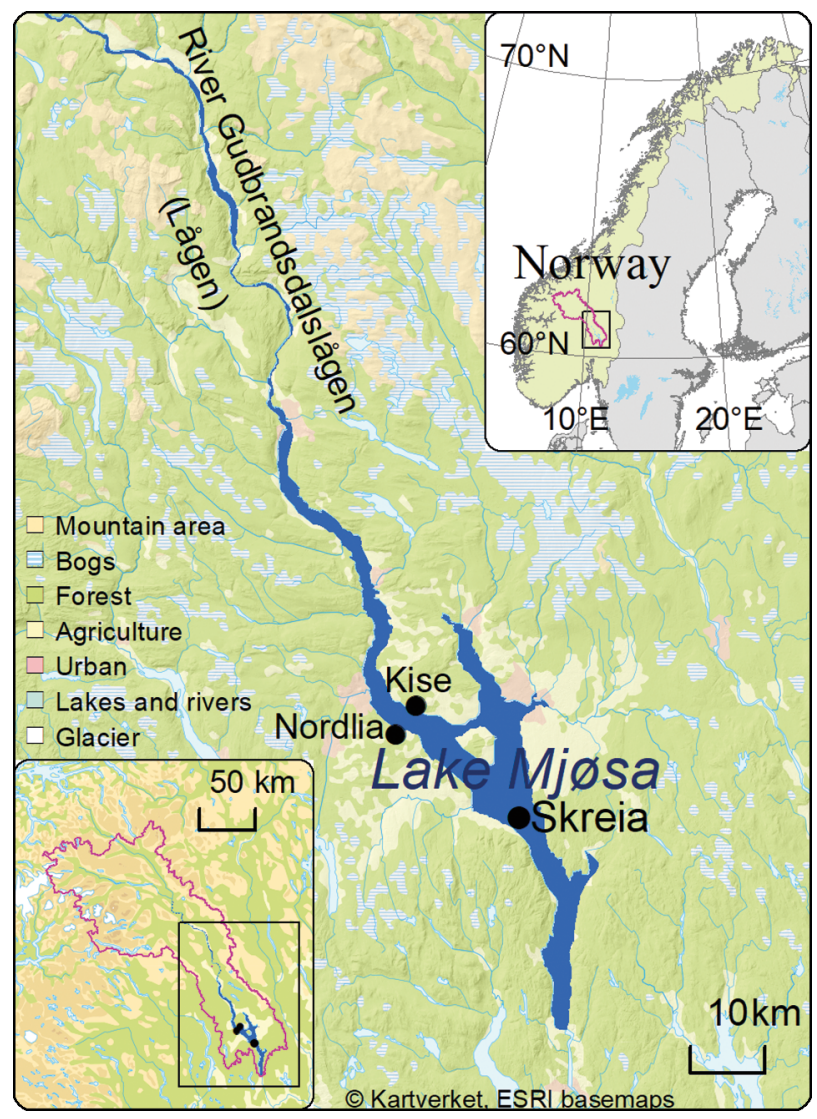

Fig. 1. Location of Lake Mjøsa and its catchment in south-east Norway
200000 people, approximately $5 \%$ of Norway's population. The lake provides important ecosystem services including drinking water, bathing and fishing, as well as habitat for a population of extremely largesized trout (Nater et al. 2018, 2021 [the latter in this Special]).

In the 1950s-1970s there were severe eutrophication problems and cyanobacterial blooms (Holtan 1990). The campaign 'Save Lake Mjøsa' (1977-1981) resulted in substantially reduced phosphorus (P) loading and re-oligotrophication. During the last two decades, the ecological status of the lake according to the national lake classification system has mostly been good (Lyche Solheim et al. 2020), which is in accordance with the management target set by the Water Framework Directive (WFD) (EC 2000). The phytoplankton and zooplankton communities of Lake Mjøsa have been monitored regularly during the last 45 yr. The main sampling point 'Skreia' is located at the deepest point $(453 \mathrm{~m})$ in the southern part of the lake (Fig. 1). Climatic changes have been observed since the 1970s: surface water temperature has increased by almost $0.4^{\circ} \mathrm{C}$ decade $^{-1}$ during the last $40 \mathrm{yr}$, the duration of stratification has increased and ice-free years have become more frequent (Hobæk et al. 2012). Ecological changes have also been detected during this period: both phytoplankton and zooplankton biomass have been reduced, and the diatom assemblage has been altered (Hobæk et al. 2012). Moreover, certain changes in zooplankton species composition have been recorded (Løvik \& Kjellberg 2003). Since the campaign, summer phytoplankton biovolume has declined from the range 1000-2000 to $<500 \mathrm{~mm}^{3} \mathrm{l}^{-1}$, and cyanobacteria very rarely cause problems. However, large pennate diatoms continue to develop at densities that are considered a nuisance during late summer (Hobæk et al. 2012). Recently, there have again been periods with high abundance of cyanobacteria up to $50 \mathrm{~mm}^{3} \mathrm{l}^{-1}$; however, this level is still within the good/moderate status boundary of $1000 \mathrm{~mm}^{3} \mathrm{l}^{-1}$ set by the Norwegian lake classification system (Lyche Solheim et al. 2020).

Lake Mjøsa is a suitable case study for investigating the ecological effects of climate change for several reasons: (1) the reported changes in surface water temperature and other climate-related variables suggest that climate change-related ecosystem effects can be expected; (2) the large volume of the lake means that it accumulates the effects of environmental change over time, making it a robust indicator of long-term climate change; (3) extensive monitoring since the 1970s has provided unique time-series data, including species-level biomass data for phytoplank- 
ton and zooplankton (Løvik \& Moe 2016), which are valuable for analysing ecosystem changes in the context of climate change. In terms of responses to climate change, the lake is representative of large stratified lakes in the boreal zone (European Broad Lake type 1; Lyche Solheim et al. 2019).

\subsection{Data}

The monitoring data included in this study (see Table 1) are (1) physical variables: lake temperature and Secchi depth (water transparency), (2) chemical variables: total $\mathrm{P}$, total nitrogen $(\mathrm{N})$, nitrate $\left(\mathrm{NO}_{3}\right)$ and silicate $\left(\mathrm{SiO}_{2}\right)$ and (3) biological variables: phytoplankton and zooplankton biomass per species. All physico-chemical variables were measured weekly, while plankton was sampled bi-weekly (i.e. every $2 \mathrm{wk}$ ), from May to October. The data series generally cover the period 1976-2014. Lake temperature was measured at several depths from $0-50 \mathrm{~m}$, while the other variables were integrated for the epilimnion $(0-10 \mathrm{~m})$. Two other climate-related variables were calculated from the depth-specific temperature data: stratification and Schmidt stability of the water column. The onset of stratification was defined by the criterion of minimum $12^{\circ} \mathrm{C}$ at $8 \mathrm{~m}$ depth. The Schmidt stability index (Winslow et al. 2013) was calculated with the $\mathrm{R}$ package 'rLakeAnalyzer' (Winslow et al. 2019).

The observations of ice cover for the years 19552014 were provided by the Norweigan Institute of Bioeconomy Research (NIBIO). Ice cover was defined by complete ice between the locations of Nordlia and Kise (Fig. 1).

Phytoplankton abundance was estimated as biovolume $\left(\mathrm{ml} \mathrm{l}^{-1}\right)$ of individual species and then converted to biomass $\left(\mathrm{mg} \mathrm{l}^{-1}\right)$ assuming a density of $1 \mathrm{mg}$ $\mathrm{ml}^{-1}$ (Utermohl technique; EN-15204). Phytoplankton abundance was analysed by total biomass, biomass of classes and biomass of individual species. In addition, the phytoplankton trophic index (PTI; Ptacnik et al. 2009) was used for analysing the trophic state of the phytoplankton community. Zooplankton abundance was analysed by total biomass and by biomass of individual species. Since most of the zooplankton genera are represented by only one species, zooplankton species will in general be referred to by their genus name.

To obtain data series with consistent frequency that covered the whole season, all variables with weekly sampling frequency were aggregated to biweekly frequency by average per fortnight. Samples from fortnight no. 11 (Week 22, late May) to fortnight no.
22 (Week 44, late October) were included in the analyses. The resulting data set was used to calculate yearly aggregated values (average and maximum); 'yearly' in this context means only the sampling period of May to October.

The methods based on time-series objects ('stl' and 'bfast'; described in Section 2.3.1) required a fixed number of observations per year. To obtain 12 values for each year, missing values for fortnight nos. 11-22 were interpolated by average, for up to 3 subsequent gaps within a year. The zooplankton data for years 1976-1981 were excluded from these analyses because of a low number of samples per year (up to 6).

\subsection{Statistical methods}

All analyses were performed in the programming environment $R$ version 3.6.3 ( $R$ Core Team 2020), through RStudio version 1.2.5033. Four main types of analyses were carried out for the data series: (1) detection and quantification of temporal trends in the environmental conditions and species abundance, with different methods as detailed below; (2) multivariate analysis of the species composition of phytoplankton and zooplankton communities, for comparison of general patterns in community structure before and after a major breakpoint; (3) more detailed exploration of changes in phenology (timing) for the environmental and biological series, by trend analysis and by visualisation of temporal patterns (generalised additive modelling [GAM] plots); and (4) multiple linear regression of yearly aggregated plankton biomass and timing to identify the most influential environmental and biological variables.

\subsubsection{Temporal trends and abrupt changes}

Simple monotonic trends in the values of environmental and biological data series were analysed by the non-parametric Mann-Kendall (MK) test (McLeod 2011). For these trend analyses, the data series were aggregated by both yearly average and yearly maximum (see Tables $1-3$ ). The outcomes of all trend tests are displayed in Figs. S1-S12, Tables S1-S3 in Supplement 1 at www.int-res.com/ articles/suppl/cr01654_supp1.pdf.

The long-term patterns in all time series with weekly or biweekly sampling were further explored by decomposition into seasonal, smoothed nonlinear trend (loess) and remaining components by the function 'stl' (Fig. 2). Abrupt changes in the data series 

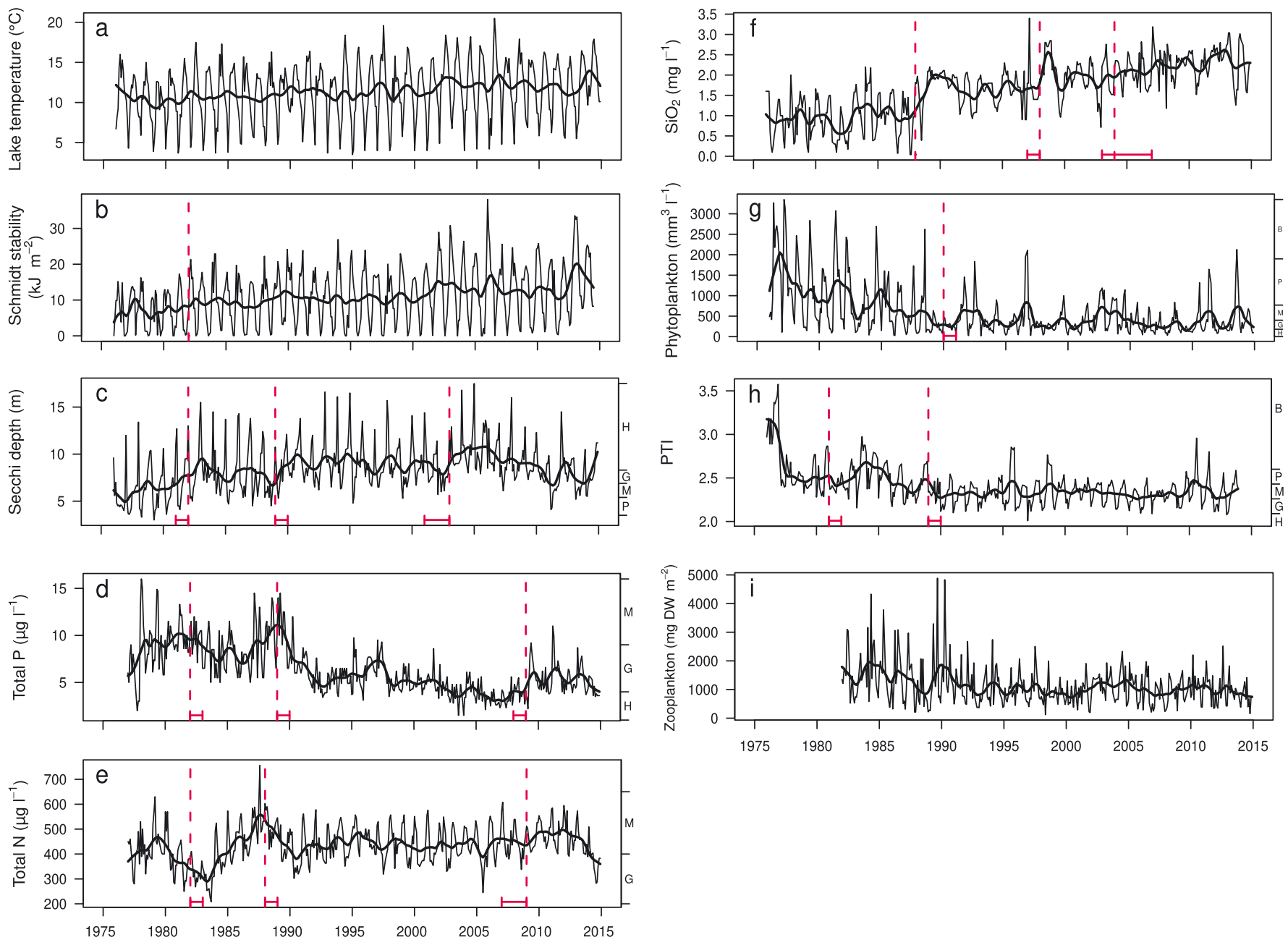

Fig. 2. Time series analyses for environmental and biological variables with biweekly (every 2 wk) or higher resolution: (a) lake epilimnion temperature, (b) Schmidt stability index, (c) Secchi depth, (d) total phosphorus (P), (e) total nitrogen (N), (f) silicate $\left(\mathrm{SiO}_{2}\right),(\mathrm{g})$ total phytoplankton biomass, (h) phytoplankton trophic index (PTI) and (i) total zooplankton biomass. Thin curves show the data; thick curves show the trend estimated by 'stl' analysis after removal of a seasonal component. Vertical red lines indicate the timing of abrupt changes; horizontal lines below these indicate the confidence interval of the timing (estimated by 'bfast' analysis). Where applicable, the ecological status class boundaries according to the European Water Framework Directive (WFD) (EC 2000) and the Norwegian lake classification system are indicated with the letters H (high), G (good), M (moderate), P (poor) and B (bad). For zooplankton biomass, the years before 1982 are excluded from the analysis due to insufficient number of observations

were analysed with 2 different methods depending on the temporal resolution. For the data series with biweekly sampling, abrupt changes in combination with both long-term trends and seasonal dynamics were analysed by the package 'bfast' (breaks for additive season and trend) (Fig. 2). This method integrates the decomposition of time series into trend, seasonal, and remainder components with methods for detecting and characterizing abrupt changes within the trend as well as seasonal variation (Verbesselt et al. 2010). For variables measured by the yearly duration, such as ice cover and duration of stratification (Fig. 3), abrupt changes were identified by methods in the package 'changepoint' (Killick \& Eckley 2013).

\subsubsection{Changes in community composition}

Changes in species composition over time for phytoplankton and zooplankton communities were tested between binary groups that were pre-defined based on temporal break points identified in the environmental data (Fig. 4). This was done using the 'adonis' function in the package 'vegan' (Oksanen et al. 2019) by calculating a multivariate analysis of 

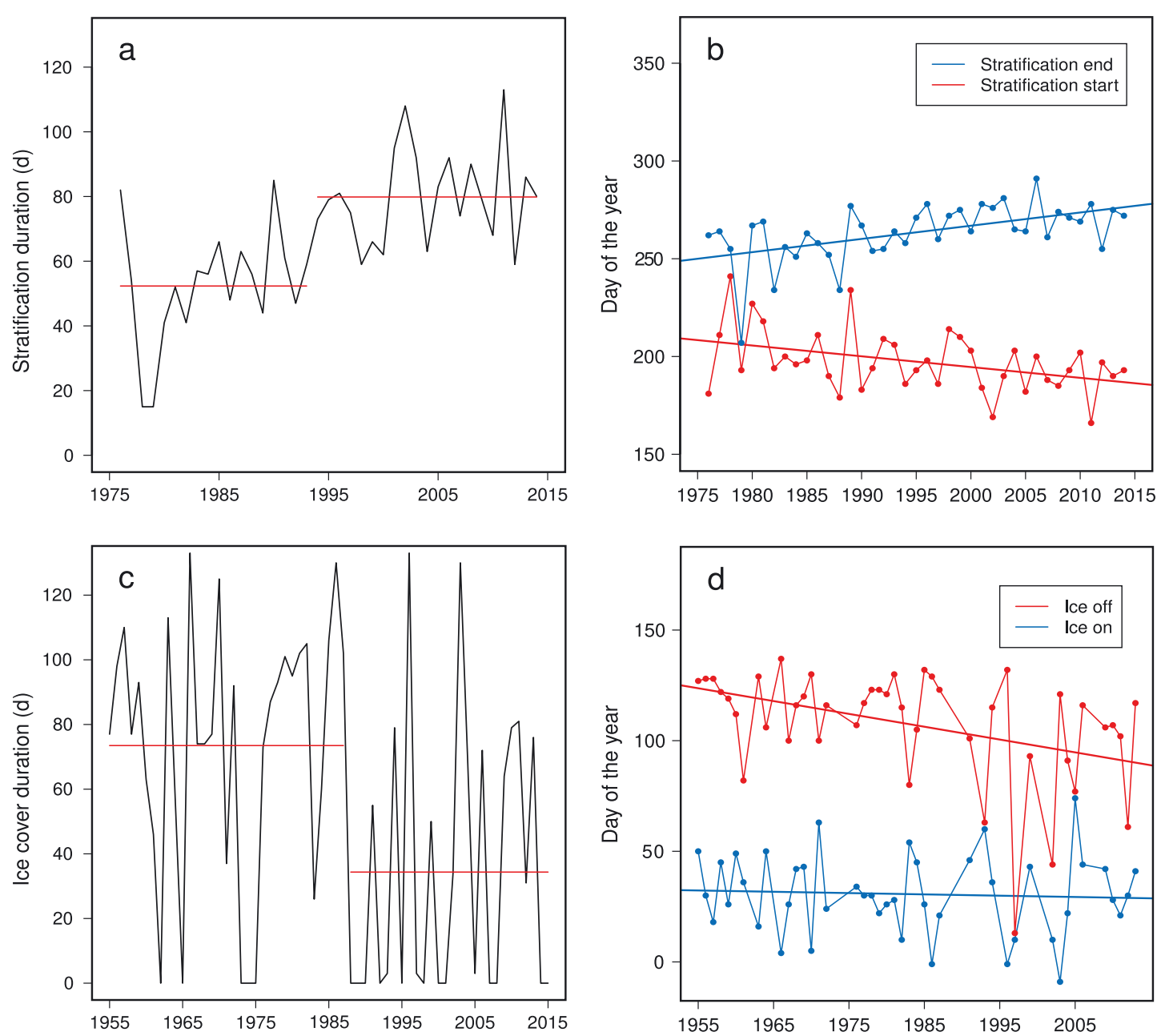

Fig. 3. Time series analyses for environmental variables with yearly resolution. (a) Yearly duration of stratification with estimated changepoint. Red horizontal lines: mean value before and after the changepoint. (b) Yearly start and end of stratification with regression lines. (c) Yearly duration of stratification with estimated changepoint. (d) Yearly start and end of ice cover with regression lines

variance using distance matrices (Anderson 2001); we used the Bray-Curtis distance matrices. Additionally, the 'betadisper' function in 'vegan' was used to analyse multivariate homogeneity of group dispersions (variances), using Bray-Curtis distance matrices. 'Betadisper' is a multivariate analogue of Levene's test of the equality of variances. This was used to compare variability in phytoplankton and zooplankton community composition (potentially a measure of $\beta$ diversity) between the pre-defined temporal groups. We used the ordination method principal coordinates analysis (PCoA) to produce low-dimensional graphical plots of the data distance matrices used for 'adonis' and 'betadisper'.

Annually aggregated and scaled data from the years 1976-2014 for phytoplankton and 1972-2014 for zooplankton were used in these analyses. Data from May to October were used to calculate first monthly and then yearly averages. If data were missing from more than 2 mo in this 6 mo period, the yearly average was excluded from the analyses. Rare taxa that did not exceed $1.5 \%$ of the total annual biomass (phytoplankton/zooplankton separately) in any year were excluded from the analyses.

\subsubsection{Changes in seasonal dynamics}

To explore the changes in phenology of individual phytoplankton classes and zooplankton species in more detail, the timing of both the maximum biomass and the central tendency of the biomass (centre of gravity) was analysed and compared across 4 time periods. An index for the timing of the central tendency 

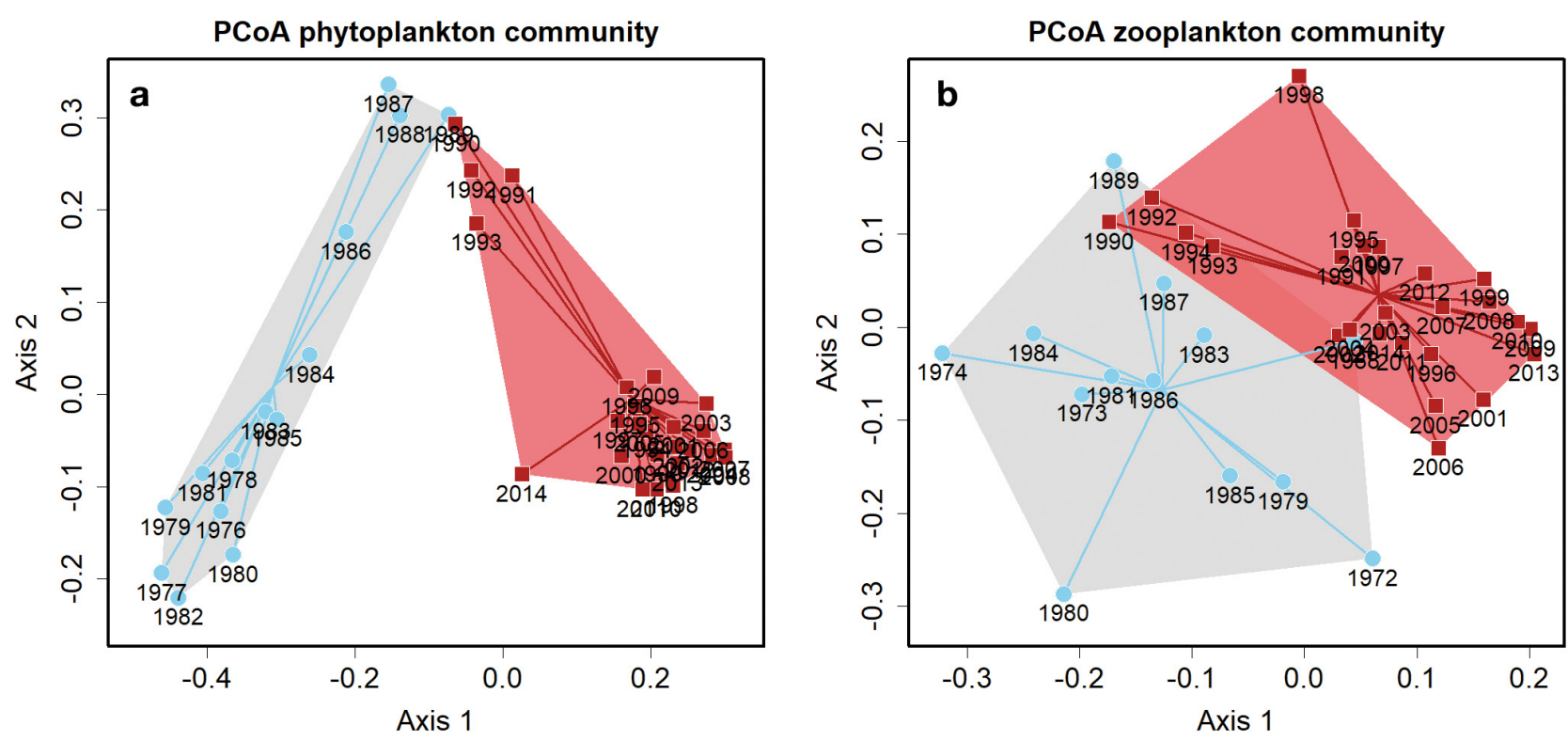

Fig. 4. Variability in (a) phytoplankton and (b) zooplankton community composition for 2 periods with significantly different species compositions for phytoplankton (different group average positions; $\mathrm{p}<0.005$ ) and zooplankton ( $\mathrm{p}<0.005$ ): 1970s-1980s (grey areas, blue lines) and 1990s-2010s (red areas, red lines). Based on the principal coordinates analysis (PCoA) distance matrices. Variability in species composition, shown by the shaded areas, is a measure of $\beta$ diversity and differed significantly between the 2 time periods for phytoplankton $(p=0.006)$ but not for zooplankton $(p=0.49)$. Lines show the distance to the average position, for each year, within each period

was calculated following Edwards \& Richardson (2004), using the fortnight co-ordinate of the centre of gravity of the area below graphs of biweekly averages:

$$
T=\sum_{i=11}^{22} i \times x_{m} / \sum_{i=11}^{22} x_{m}
$$

where $x_{m}$ is the average biomass in fortnight $i(11=$ late May, 22 = late October). Long-term changes in the timing of central and maximum biomass were analysed by the MK test (Figs. S9-S12). The same approach was applied for the environmental variables including the total phytoplankton and zooplankton biomasses (Figs. S3 \&S4, see Table 1). Trends in the yearly start and end date of stratification and ice cover were also analysed by the MK test.

The seasonal dynamics of selected environmental and biological data were also visualized as smoothed curves estimated by GAMs. The time series were split into 4 decades (1975-1984, 1985-1994，1995-2004 and 2005-2014) to explore the long-term changes in patterns of seasonal dynamics (Figs. 5-7).

\subsubsection{Multiple regression of plankton biomass and timing}

The relationships between variation in biomass and timing of the plankton communities and relevant environmental variables were also analysed by multiple regression (see Table S4 in Supplement 2 at www.int-res.com/articles/suppl/cr01654_supp2.xlsx). The yearly average total biomass of phytoplankton was analysed with the following predictor variables: ice-off day and stratfication onset (Julian days); Schmidt stability, temperature, total $\mathrm{N}$ and total $\mathrm{P}$ (yearly averages). Total zooplankton biomass was analysed with the same predictor variables, except that total $\mathrm{N}$ and $\mathrm{P}$ were replaced by chlorophyll $a$ (chl a) (as a proxy for phytoplankton biomass). For each phytoplankton class, the timing of peak biomass was analysed with the same predictor variables as the total biomass, except that yearly temperature was replaced with spring temperature. For each zooplankton species, the timing of the peak biomass was regressed against the same 4 climate-related variables, as well as the timing of peak biomass of the dominating phytoplankton classes (Bacillariophyceae, Chrysophyceae and Cryptophyceae). The performance of the global models was compared with all possible subsets by Akaike's information criterion (AIC), using the function 'dredge' of the R package 'MuMIn' (Barton 2020). For each response variable, the 10 alternative models with the lowest AIC are stored in Table S4. All top-ranked models with a difference in AIC less than 2 were inspected more closely, and the predictor variables occurring most 

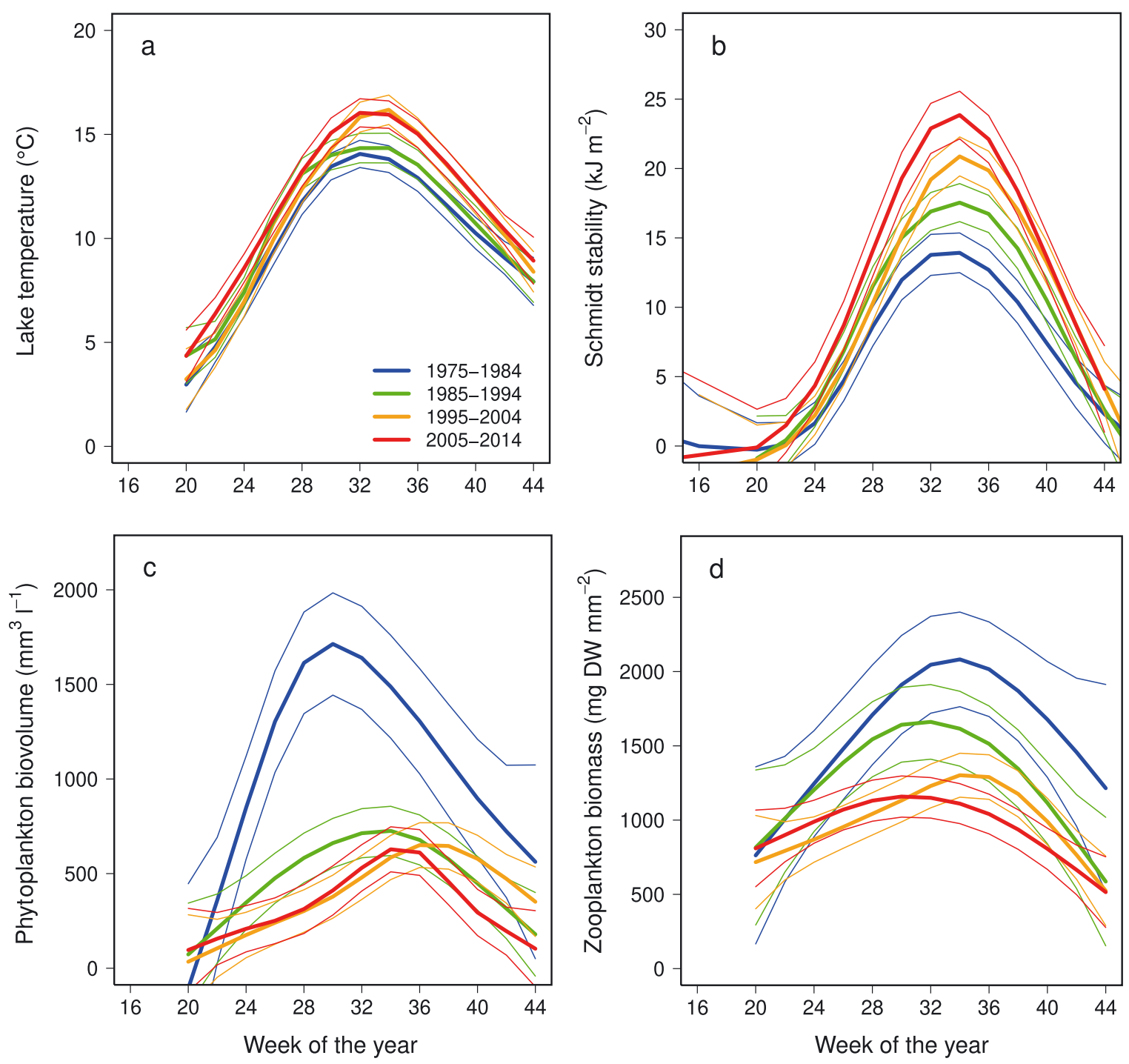

Fig. 5. Seasonal dynamics of selected environmental variables (see Table 1). Within each 10 yr period, the seasonal dynamics of each variable are estimated by generalised additive models. Thick and thin curves: estimated mean and $95 \%$ confidence intervals, respectively

frequently in this subset were considered the most significant predictor variables.

\section{RESULTS AND DISCUSSION}

\subsection{Environmental conditions}

The epilimnion temperature of Lake Mjøsa (Fig. 2a) has increased steadily during the last 4 decades (Table 1a). The yearly average increased from $10.1^{\circ} \mathrm{C}$ in the decade $1975-1984$ to $11.9^{\circ} \mathrm{C}$ in the decade 2005-2014. Over the same period, the average of the yearly recorded maximum temperatures increased from $15.4-16.5^{\circ} \mathrm{C}$. The lake temperature has continued to increase in the years following our study period, with the highest maximum temperature recorded in 2018 (Lyche Solheim et al. 2020). Stability of the water column measured by the Schmidt stability index (Fig. 2b) has increased during this period (Table 1). There were no abrupt changes in the increase of temperature or stability according to the 'bfast' analysis (Fig. 2a,b). The timing of the central tendency has shifted to later in the season, while the timing of the peak values is unchanged according to the MK trend analysis (Table 1). This pattern is reflected in the plots of seasonal dynamics aggregated by decades (Fig. 5a,b). 

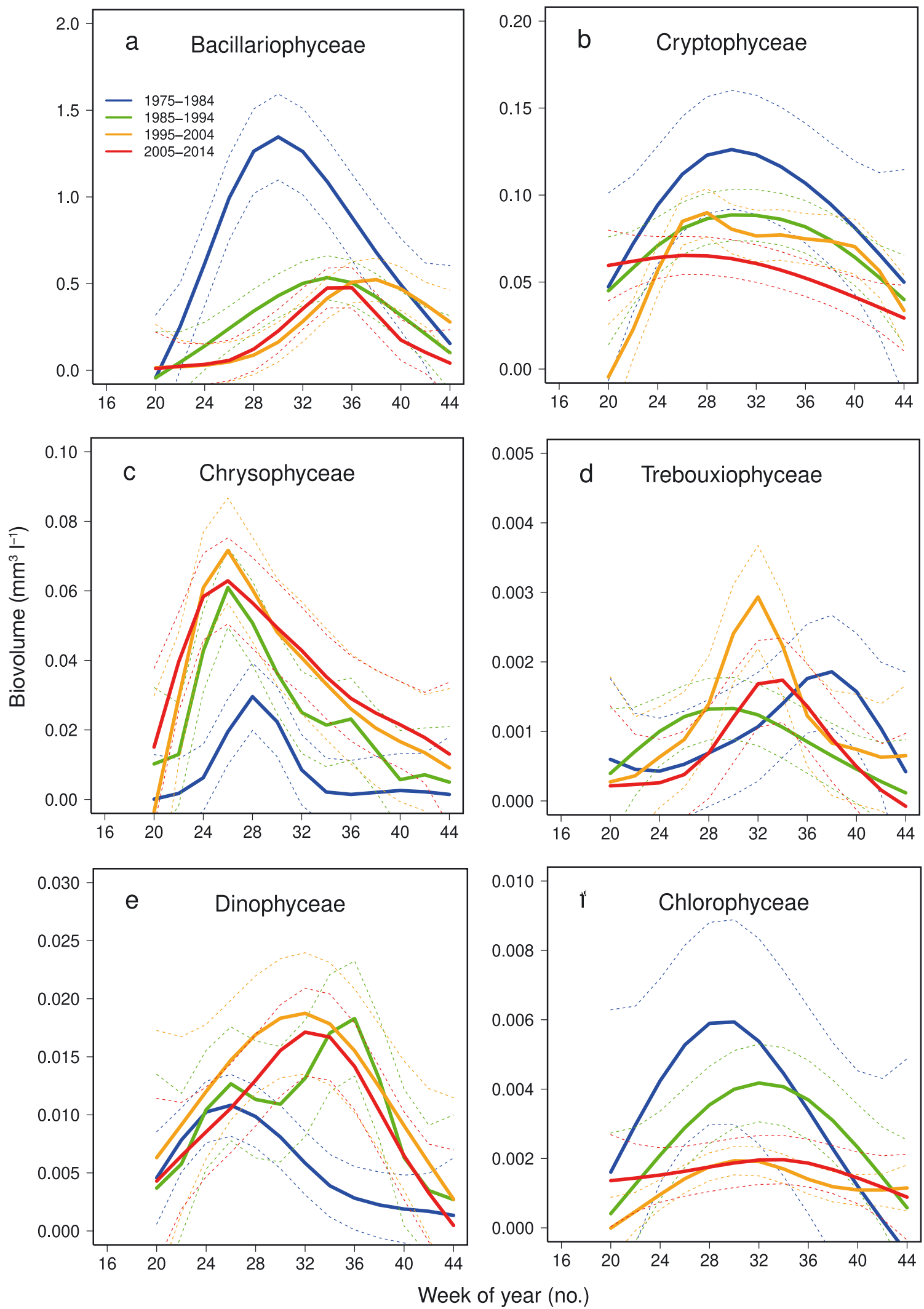

Fig. 6. Seasonal dynamics of the 6 phytoplankton classes showing significant trends in timing (see Table 2). Note the different $y$-axis scales. Thick and thin (dashed) curves: estimated mean and $95 \%$ confidence intervals, respectively. For more details, see Fig. 5 

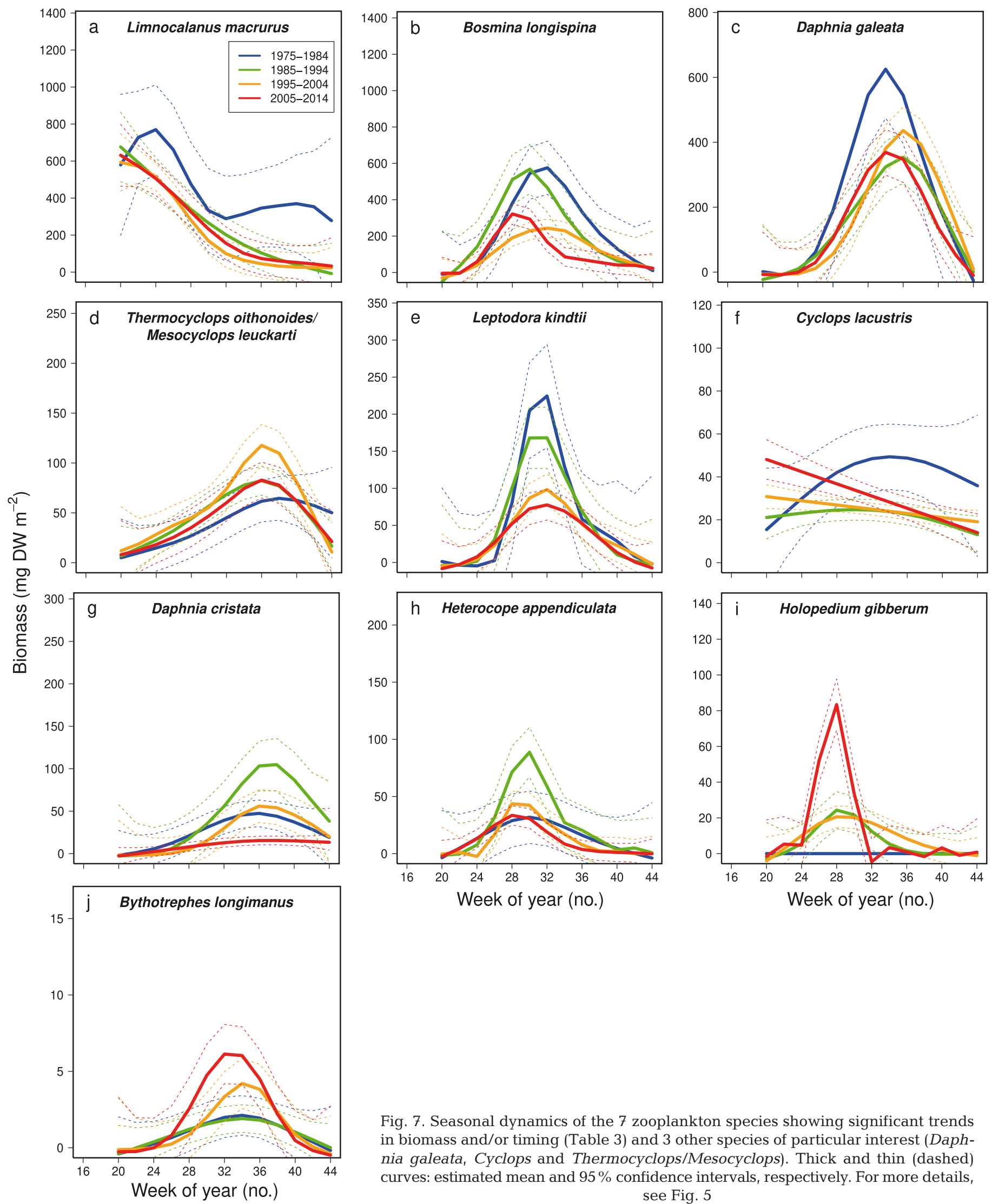

Fig. 7. Seasonal dynamics of the 7 zooplankton species showing significant trends in biomass and/or timing (Table 3 ) and 3 other species of particular interest (Daphnia galeata, Cyclops and Thermocyclops/Mesocyclops). Thick and thin (dashed) curves: estimated mean and $95 \%$ confidence intervals, respectively. For more details, see Fig. 5 
Table 1. Trend analysis of environmental monitoring data with (a) weekly or biweekly (every 2 wk) sampling frequency and (b) variables with yearly duration. The test results of (a) are reported in Table S1 in Supplement 1 (www.int-res.com/articles/suppl/ cr01654_supp1.pdf). Arrows denote increasing values $(\uparrow)$, decreasing values $(\downarrow)$, earlier timing $(\leftarrow)$ and later timing $(\rightarrow)$ of average (central) and peak values; zero denotes no significant trend. Significance levels: bold arrows denote $p<0.01$, normal font denotes $\mathrm{p}<0.05$, arrows in parentheses denote $\mathrm{p}<0.1$, and 0 denotes $\mathrm{p} \geq 0.1$. The arrows under 'Summary' illustrate the combined trends of value and timing. PTI: phytoplankton trophic index; DW: dry weight

\begin{tabular}{|c|c|c|c|c|c|c|}
\hline (a) Variable & Units & $\begin{array}{l}\text { Average } \\
\text { value }\end{array}$ & Peak value & $\begin{array}{l}\text { Timing of central } \\
\text { value }\end{array}$ & $\begin{array}{c}\text { Timing of peak } \\
\text { value }\end{array}$ & Summary \\
\hline Lake temperature & ${ }^{\circ} \mathrm{C}$ & $\uparrow$ & $\uparrow$ & $\rightarrow$ & 0 & $\pi$ \\
\hline Schmidt stability & $\mathrm{kJ} \mathrm{m}{ }^{-2}$ & $\uparrow$ & $\uparrow$ & $\rightarrow$ & 0 & $\pi$ \\
\hline Secchi depth & $\mathrm{m}$ & $\uparrow$ & $(\uparrow)$ & 0 & $\leftarrow$ & $\pi$ \\
\hline Total P & $\mu g l^{-1}$ & $\downarrow$ & $\downarrow$ & $\rightarrow$ & 0 & 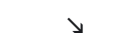 \\
\hline Total N & $\mu g l^{-1}$ & 0 & 0 & $(\rightarrow)$ & 0 & $\rightarrow$ \\
\hline $\mathrm{NO}_{3}$ & $\mu \mathrm{gl}^{-1}$ & $\uparrow$ & $\uparrow$ & 0 & 0 & $\uparrow$ \\
\hline $\mathrm{SiO}_{2}$ & $\mu \mathrm{gl}^{-1}$ & $\uparrow$ & $\uparrow$ & $\rightarrow$ & 0 & $\pi$ \\
\hline Phytoplankton & $\mathrm{mm}^{3} \mathrm{l}^{-1}$ & $\downarrow$ & $\downarrow$ & $(\rightarrow)$ & $\rightarrow$ & $\checkmark$ \\
\hline PTI & - & $\downarrow$ & $\downarrow$ & $\rightarrow$ & 0 & $\searrow$ \\
\hline Zooplankton & $\mathrm{mg} \mathrm{DW} \mathrm{m}^{-2}$ & 0 & $\downarrow$ & $\leftarrow$ & 0 & $\swarrow$ \\
\hline (b) Variable & Units & $\begin{array}{l}\text { Timing of } \\
\text { start }\end{array}$ & $\begin{array}{l}\text { Timing of } \\
\text { end }\end{array}$ & & & \\
\hline Stratification & no. of days & $\leftarrow$ & $\rightarrow$ & & & \\
\hline Ice cover & no. of days & 0 & $\leftarrow$ & & & \\
\hline
\end{tabular}

The duration of lake stratification, which is closely related to lake temperature, increased significantly during the 4 decades (Table 1b). The most significant change in duration was estimated to occur during the early 1990s, from 52-79 d (Fig. 3a). The increased duration of stratification was due later end of stratification in late summer or autumn, as well as earlier onset of stratification in spring or early summer (Fig. 3b).

The duration of ice cover dropped most abruptly from the late 1980s (73 vs. 34 di Fig. 3c). The shorter ice cover duration was mostly caused by earlier melting during spring (Fig. 3d, Table 1b). In addition, icefree winters have become more common (Fig. 3c; not accounted for in the trend analysis in Table $1 \mathrm{~b}$ ).

Nutrient concentrations displayed large fluctuations in the 1970s-1980s (Fig. 2d-f). Total P declined through the 1990s and early 2000s, followed by an increase from the 2000s (Fig. 2d). The most abrupt decrease in total P occurred in 1989-1990, a decade after the Lake Mjøsa campaign was launched to reduce P emissions. Total N increased in the late 1980s and then remained constant throughout the 1990s, but also displayed a slight increase from the mid2000s, with a recent drop in the 2010s (Fig. 2e). An explanation for the recent increases and fluctuations in nutrient concentrations may be changes in the patterns of precipitation, which affects the runoff of $\mathrm{P}$ and $\mathrm{N}$ loads from the catchment (Lyche Solheim et al. 2020).
$\mathrm{SiO}_{2}$ has increased steadily since the late 1980s (Fig. 2f), unlike the other nutrients. A likely explanation is reduced uptake of $\mathrm{SiO}_{2}$ by diatoms (Bacillariophyceae) due to the reduced biomass of this phytoplankton class (Table 2, Fig. 6a).

The trend in Secchi depth (water transparency; Fig. 2c) mostly mirrors the trends in total $\mathrm{P}$ and reflects the degree of eutrophication. Secchi depth increased from 6-7 $\mathrm{m}$ in the late $1970 \mathrm{~s}$ to $8-10 \mathrm{~m}$ in the 1990 s and then decreased during the late 2000s.

\subsection{Phytoplankton communities}

\subsubsection{Phytoplankton total biomass and species composition}

The total phytoplankton biomass showed a declining trend from the late 1970s until 1990 (Fig. 2g; estimated breakpoint indicated by a vertical red line), after which the mean biomass fluctuated at a relatively low level. This breakpoint coincided with the strong reduction of total $\mathrm{P}$ following the estimated breakpoint around 1990 (Fig. 2d). Total P is the most consistent predictor of yearly variation in total phytoplankton biomass, together with ice-off day (Table S4a). A direct effect of earlier ice-off on reduced phytoplankton total biomass is not very plausible. A more likely explanation is that the effect of ice-off date reflects a 
Table 2. Trend analysis for biomass and seasonal dynamics of phytoplankton classes. The test statistics are reported in Table S2 in Supplement 1 (www.int-res.com/articles/suppl/cr01654_supp1.pdf). Taxa are sorted by their percentage of the total biomass. Arrows denote higher biomass $(\uparrow)$, lower biomass $(\downarrow)$, earlier timing $(\leftarrow)$, later timing $(\rightarrow)$ and combinations of these. For further explanation, see Table 1

\begin{tabular}{|c|c|c|c|c|c|c|}
\hline Taxon & $\begin{array}{c}\text { Percentage } \\
\text { of total biomass }\end{array}$ & $\begin{array}{l}\text { Average } \\
\text { biomass }\end{array}$ & $\begin{array}{c}\text { Peak } \\
\text { biomass }\end{array}$ & $\begin{array}{c}\text { Timing of central } \\
\text { biomass }\end{array}$ & $\begin{array}{c}\text { Timing of peak } \\
\text { biomass }\end{array}$ & Summary \\
\hline Bacillariophyceae & 50.9 & $\downarrow$ & $\downarrow$ & $\rightarrow$ & $\rightarrow$ & $\checkmark$ \\
\hline Cryptophyceae & 20.8 & $\downarrow$ & $\downarrow$ & 0 & $(\leftarrow)$ & $\swarrow$ \\
\hline Chrysophyceae & 9.4 & $\uparrow$ & $(\uparrow)$ & $\rightarrow$ & 0 & $\pi$ \\
\hline Synurophyceae & 3.5 & $\downarrow$ & $\downarrow$ & 0 & 0 & $\downarrow$ \\
\hline Cyanophyceae & 3.2 & $\downarrow$ & $\downarrow$ & 0 & 0 & $\downarrow$ \\
\hline Dinophyceae & 3.1 & $\uparrow$ & 0 & $\rightarrow$ & $\rightarrow$ & $\pi$ \\
\hline Prymnesiophyceae & 1.2 & $\downarrow$ & $\downarrow$ & 0 & 0 & $\downarrow$ \\
\hline Chlorophyceae & 0.56 & $\downarrow$ & $\downarrow$ & $\rightarrow$ & $(\rightarrow)$ & 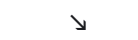 \\
\hline Choanoflagellatea & 0.51 & $\downarrow$ & $\downarrow$ & 0 & 0 & $\downarrow$ \\
\hline Trebouxiophyceae & 0.29 & 0 & 0 & 0 & $\rightarrow$ & $\rightarrow$ \\
\hline Sum & 93.3 & & & & & \\
\hline
\end{tabular}

correlation with total $\mathrm{P}(\mathrm{R}=0.38)$ or that it incorporates trophic interactions with zooplankton (as discussed below). The secondary predictors of higher phytoplankton biomass were higher temperature and lower thermal stability, which can benefit phytoplankton growth by higher metabolism and by more circulation of nutrients, respectively.

The PTI (Fig. 2h), which is a community-based indicator of eutrophication, started indicating reduced nutrient levels at an earlier stage (late 1980s) than total phytoplankton biomass. Moreover, this index tends to reflect the recent increase and fluctuation in nutrients that have occurred since the late 2000s more clearly than total phytoplankton biomass.

Based on the estimated breakpoint in 1990 (Fig. 2d), the phytoplankton series was divided into 2 groups (1972-1989 and 1990-2014) for analysis of changes in species composition. There was a significant difference between these 2 groups ('adonis', $\mathrm{p}<0.0005$; Fig. 4a). There was also a significant difference in the variability in phytoplankton community composition between the 2 time periods ('betadisper', $p=0.004$ ), with variability being lower in the most recent period. Reduced nutrient levels and/or increased water temperature could thus potentially have contributed to lower phytoplankton variation or species turnover.

\subsubsection{Temporal trends and seasonal dynamics of phytoplankton classes}

The results of the MK trend analyses for biomass of individual phytoplankton classes (Figs. S5 \& S6) are summarised in Table 2. A declining trend in biomass was significant (all $\mathrm{p}<0.10$ ) for 7 of the 10 phytoplankton classes: Bacillariophyceae, Cryptophyceae, Cyanophyceae, Synurophyceae, Chlorophyceae, Choanoflagellatea and Prymnesiophyceae. These taxa comprise $78.1 \%$ of the total phytoplankton biomass (averaged across all samples). Increased biomass was found for only 2 classes (Chrysophyceae and Dinophyceae), comprising $12.5 \%$ of the total phytoplankton biomass.

The peak in total phytoplankton biomass has generally shifted to later in the season (Fig. 5c). Analysed trends in phenology for phytoplankton classes (Figs. S9 \& S10) are summarised in Table S2 (p values) and in Table 2 (direction of trends). A significant trend in later timing (central and/or peak biomass) was found for 5 of the 10 phytoplankton classes: Bacillariophyceae, Chrysophyceae, Dinophyceae, Chlorophyceae and Trebouxiophyceae, comprising $67.4 \%$ of the total phytoplankton biomass (all $\mathrm{p}<0.10$ ). Only one class showed earlier timing $(p=0.066)$ : Cryptophyceae, containing $20.8 \%$ of the phytoplankton biomass. Although the timing of the different classes has mostly shifted in the same direction, the more detailed patterns and therefore the underlying processes have varied among these taxa.

The most dominant class, Bacillariophyceae (diatoms; Fig. 6a), reflected the general pattern of the phytoplankton community with lower and later peak biomass over the decades (Fig. 5c). Visualisation of trends in seasonal dynamics (Fig. 6a) suggests that the later timing of the peak is due to slower population growth in spring during the last decades. The pattern is consistent with the regression analysis which clearly identified decreased total P as the most 
consistent predictor variable for the later timing of diatom peaks (Table S4b). Diatoms might be expected to benefit from earlier stratification (Fig. 3b); an earlier peak in biomass was also correlated with earlier stratification onset for 2 of the 5 best candidate regression models. Earlier spring peak of diatoms has been observed in several other lakes, such as the large lakes of southern Sweden, and has been attributed to warmer winters (Weyhenmeyer 2001). However, the diatom dynamic in Lake Mjøsa is somewhat unusual due to the lack of a proper spring bloom throughout the monitoring period. Another possibility is that diatoms have become more limited by the earlier peaks of grazing zooplankton taxa such as Holopedium and Limnocalanus (Kagami et al. 2005), although such trophic interactions were not manifested as correlations between the timing of these taxa.

The population growth of Cryptophyceae has started earlier in the last decade. The trend analysis indicates an earlier timing of the peak biomass $(\mathrm{p}=$ 0.066), but not of the central biomass ( $p=0.866)$. However, the estimated population growth curve (Fig. 6b) indicates that growth must have started a few weeks before the monitoring period, which started in late May. These are flagellate species that can move towards light and start their population growth below the ice. The earlier peaks of Cryptophyceae were most consistently correlated with higher thermal stability (Table S4b) rather than earlier ice-off. Two of the models with slightly lower fit suggested higher spring temperature and earlier stratification as significant predictor variables. Similarly, a forward shift of the phytoplankton bloom in Lake Washington was explained by earlier onset of thermal stratification in spring (Winder \& Schindler 2004).

Chrysophyceae (Fig. 6c) showed the most significant increase in biomass. This class contains mixotroph species which can feed on bacteria in addition to nutrients. The mixotroph species may have benefited from a competitive advantage over autotroph species as the total P concentration declined. Chrysophyceae also appears to have had a more rapid spring increase in the last 3 decades (Figs. 6c \& S10d), although such a trend in peak biomass was not statistically significant. The species are flagellate and could therefore benefit from earlier ice-off (cf. Cryptophyceae). The trend analysis, on the contrary, showed a trend towards later timing of the central biomass (Fig. S9d). The timing of Chrysophyceae is positively correlated with the concentration of total $\mathrm{P}$ (Table S4b). This trend can therefore be caused by late blooms of certain species that benefit from reduced competition with Cyanophyceae for nutrients.

Trebouxiophyceae (Fig. 6d), a group of green algae, showed a statistical trend of later timing of peak biomass, but there was no clear pattern in the seasonal dynamics across the decades.

The increased biomass of Dinophyceae (dinoflagellates; Fig. 6e) showed a growth pattern similar to the Chrysophyceae (Fig. 6b): later timing of peak and central biomass due to continued growth during summer compared to the 1970-1980s. The later peaks are most consistently correlated with later onset of stratification and secondarily by higher thermal stability and higher total $\mathrm{N}$ concentrations (Table S4b). Dinophyceae are also mixotroph species which can benefit from a competitive advantage with autotroph algae under low total P conditions. Dinoflagellates are large species with low edibility for zooplankton. Reduced competition from Cyanophyceae is, therefore, a more likely explanation than reduced grazing for the prolonged growth and increased biomass. The apparent double peak in the 1980s-1990s may have been caused by a late bloom of certain species within the class.

The Chlorophyceae (green algae; Fig. 6f) showed a pattern similar to the Bacillariophyceae (Fig. 6a), with a later peak caused by slower growth. Considering environmental variables, later peaks for this class are correlated primarily with earlier ice-off days (Table S4b), which is not meaningful as a direct cause. Higher grazing pressure in early spring by zooplankton such as Holopedium and Limnocalanus may also be a more reasonable explanation in this case.

Cyanophyceae (cyanobacteria) had an extreme reduction in biomass due to lower total $\mathrm{P}$, although there has been a slight increase in blooms in recent years (Fig. S6f). There has not been a consistent change in the timing of blooms, which can be highly variable, nor was there any consistent correlation with predictor variables (Table S4b). More cyanobacteria blooms have been reported in recent years following our study period (Lyche Solheim et al. 2020).

\subsection{Zooplankton communities}

\subsubsection{Zooplankton total biomass and species composition}

The zooplankton biomass declined during most of the $40 \mathrm{yr}$ period, except for a peak during the mid1980s. The 'bfast' analysis did not indicate any 
abrupt decrease in zooplankton biomass. The yearly average biomass was reduced by $27 \%$ from $1316 \mathrm{mg}$ DW m ${ }^{-2}$ in the period $1985-1994$ to $960 \mathrm{mg} \mathrm{DW} \mathrm{m}^{-2}$ in the period 2009-2014. The variation in zooplankton biomass was best explained by the phytoplankton biomass, measured by chl a (Table S4c). The declining trend in phytoplankton biomass implies less food for herbivore zooplankton species, which in turn provided less food for the carnivore species. Iceoff day was the second most consistent predictor variable for total zooplankton biomass (Table S4c). The positive correlation suggests that the observed trend of earlier ice-off day (Fig. 3d) can contribute to the observed declining trend in zooplankton biomass; potential explanations will be discussed further below. The trends in zooplankton biomass (Figs. S7 \& S8) and phenology (Figs. S11 \& S12) were further analysed for 20 individual species. The results summarised in Table 3 are for the 13 species with the highest abundance, comprising in total $99.9 \%$ of the biomass.

Only 3 of the 13 selected zooplankton species showed a significant negative trend during the whole period (Table 3 ), comprising $18 \%$ of the biomass (Bosmina, Leptodora and Daphnia cristata). Two species showed increased biomass (Holopedium and Bythotrephes), but these comprised only $0.9 \%$ of the biomass. The herbivore Holopedium was virtually absent in the 1970s-1980s, but has occurred in high densities since the 2010s. It is an indicator of oligotrophic conditions and typically benefits from lower $\mathrm{pH}$. However, there is no evidence of reduced
$\mathrm{pH}$ in lake Mjøsa for the period where $\mathrm{pH}$ observations are available (1986-2014). Another plausible explanation for its increase is reduced competition from Daphnia (Hessen et al. 1995, Carter et al. 2017). For the large-bodied carnivore Bythotrephes, a likely explanation is reduced predation by fish.

There was a significant difference in zooplankton community composition between the pre-defined groups of years 1973-1989 and 1990-2014 ('adonis', $\mathrm{p}<0.0005$; Fig. 4b). However, there was no significant difference in the variability in zooplankton community composition between the 2 time periods ('betadisper', $\mathrm{p}=0.49$ ).

Four species displayed a trend in earlier timing of peak biomass (either central or maximum tendency, all $\mathrm{p}<0.05$; Table 3): Limnocalanus, Bosmina longispina, Heterocope and Holopedium. These comprised $38 \%$ of the total zooplankton biomass. However, there were large variations among the species, therefore the long-term trends in seasonal dynamics of each species should be considered separately.

\subsubsection{Temporal trends and seasonal dynamics of zooplankton species}

The peak in total zooplankton biomass (Fig. 5d), in contrast to phytoplankton biomass (Fig. 5c), appeared to be shifted to slightly earlier in the season. However, the trend in timing was not significant for the whole zooplankton community combined, and there was large variation among the taxa.

Table 3. Trend analysis for biomass and seasonal dynamics of zooplankton species. The test statistics are reported in Table S3 in Supplement 1 (www.int-res.com/articles/suppl/cr01654_supp1.pdf). Only taxa contributing minimum $0.10 \%$ of the total biomass are included in the summary. For further explanation, see Table 2

\begin{tabular}{|c|c|c|c|c|c|c|c|}
\hline Taxon & Functional group & $\begin{array}{l}\text { Percentage of } \\
\text { total biomass }\end{array}$ & $\begin{array}{l}\text { Average } \\
\text { biomass }\end{array}$ & $\begin{array}{c}\text { Peak } \\
\text { biomass }\end{array}$ & $\begin{array}{l}\text { Timing of } \\
\text { central biomass }\end{array}$ & $\begin{array}{l}\text { Timing of peak } \\
\text { S biomass }\end{array}$ & Summary \\
\hline Eudiaptomus gracilis & Herbivore Calanoida & 36.6 & 0 & 0 & 0 & 0 & 0 \\
\hline Limnocalanus macrurus & Omnivore Calanoida & 23.6 & 0 & 0 & $(\leftarrow)$ & $\leftarrow$ & $\leftarrow$ \\
\hline Bosmina longispina & Herbivore Cladocera & 12.3 & $\downarrow$ & $\downarrow$ & $(\leftarrow)$ & 0 & $\kappa$ \\
\hline Daphnia galeata & Herbivore Cladocera & 12.0 & 0 & 0 & 0 & 0 & 0 \\
\hline $\begin{array}{l}\text { Thermocyclops oithonoides/ } \\
\text { Mesocyclops leuckarti }\end{array}$ & Omnivore Cyclopoida & 4.5 & 0 & 0 & 0 & 0 & 0 \\
\hline Leptodora kindtii & Carnivore Cladocera & 3.2 & $\downarrow$ & $\downarrow$ & 0 & 0 & $\downarrow$ \\
\hline Cyclops lacustris & Omnivore Cyclopoida & 3.0 & 0 & 0 & 0 & 0 & 0 \\
\hline Daphnia cristata & Herbivore Cladocera & 2.2 & $\downarrow$ & $\downarrow$ & 0 & 0 & $\downarrow$ \\
\hline Heterocope appendiculata & Omnivore Calanoida & 1.3 & 0 & 0 & $\leftarrow$ & $\leftarrow$ & $\leftarrow$ \\
\hline Holopedium gibberum & Herbivore Cladocera & 0.78 & $\uparrow$ & $\uparrow$ & $\leftarrow$ & $\leftarrow$ & $\pi$ \\
\hline Polyphemus pediculus & Carnivore Cladocera & 0.26 & 0 & 0 & 0 & 0 & 0 \\
\hline Bythotrephes longimanus & Carnivore Cladocera & 0.099 & $\uparrow$ & $\uparrow$ & 0 & 0 & $\uparrow$ \\
\hline Bosmina longirostris & Herbivore Cladocera & 0.096 & 0 & 0 & 0 & 0 & \\
\hline Sum & & 99.9 & & & & & \\
\hline
\end{tabular}


Limnocalanus macrurus showed no significant change in biomass but earlier timing (Table 3), which was caused by an earlier start of population growth (Fig. 7a). It is not possible to estimate the timing of the biomass peak for the last 2 decades because it typically occurred before the monitoring season started. Nevertheless, it can be inferred from Fig. $7 \mathrm{a}$ that the peak occurred earlier during the 1990s-2000s than during the 1970s-1980s. Higher thermal stability was the most consistent predictor of earlier peaks (Table S4d). Earlier warming of the water in spring might give this cold-tolerant species an even earlier head start and competitive advantage relative to other species. Conversely, phenological delays have been reported for this species in years with unusually low spring and summer water temperatures (Pawlowski et al. 2018). Other plausible explanations for the earlier start are earlier growth of Cryptophyceae and variations in predation by fish and the larger crustacean Mysis relicta.

B. longispina (Fig. 7b) most clearly reflected the general pattern of earlier peaks of zooplankton biomass (Fig. 5d). The earlier peak was caused by an earlier decline in population growth in summer. The earlier timing of the peak biomass of this species showed strong consistency with higher spring temperature (Table S4d). However, such a climatic effect should have been reflected in earlier or quicker population growth, which is not reflected in Fig. $7 \mathrm{~b}$. Therefore, a more likely explanation is reduced phytoplankton biomass as food.

According to the trend analysis (Table 3), the species Daphnia galeata, Thermocyclops oithonoides/ Mesocyclops leuckarti and Cyclops lacustris showed no significant trends in biomass or timing, while Leptodora kindtii and D. cristata showed declining trends in biomass only. Nevertheless, closer inspection of the seasonal dynamics (Fig. $7 \mathrm{c}-\mathrm{g}$ ) revealed more long-term patterns for some of the species.

D. galeata biomass (Fig. $7 \mathrm{C}$ ) decreased from the first to the second decade and then increased slightly, while the competitor D. cristata increased from the first to the second period, followed by a decrease. These species are important prey for fish, especially the larger D. galeata. The fluctuations in biomass, both short- and long-term, are probably regulated by fish and invertebrate predators as well as food or temperature.

Thermocyclops/Mesocyclops biomass (Fig. 7d) increased during the first decades, but then declined in the last decade. These species prefer warm water and could therefore be expected to benefit from rising temperature. However, the decrease of these omni- vorous species in the last decade must have other explanations, such as reduced food availability caused by stronger competition with cladocerans and/or lesser amounts of animal food items.

The timing of the C. lacustris peak biomass (Fig. 7f) has apparently shifted from late summer (first decade) to before the sampling period. The estimated population growth trajectories for the last 3 decades (which show only the declining phase) indicate that Cyclops has reached higher abundance by Week 20 in later decades, and therefore that the early spring growth has started earlier or been more rapid. This species prefers cold water and might get an earlier start with earlier warming of the water. It may also have benefitted from the more rapid increase of Chryptophyceae (Fig. 6b).

Heterocope appendiculata (Fig. 7h) increased from the first to the second decade, then decreased again. This omnivore species is a competitor of Limnocalanus, but can also feed on Limnocalanus if it develops earlier. The earlier seasonal peak of this species seems to be related to earlier decline rather than earlier or more rapid growth. The most consistent predictor was the timing of peaks in Chrysophyceae biomass (Table S4d); this correlation suggests that the phenology of Heterocope is more strongly influenced by resources than by climatic conditions directly. This species starts producing resting eggs when the population reaches high abundance during summer, which will result in a decline in the sampled biomass.

Holopedium gibberum (Fig. 7i) showed both increasing biomass and earlier peaks, particularly in the last decade. The seasonal plot indicates that the earlier peak in biomass was due to more rapid growth in spring. This rapid growth can be related to higher spring temperatures, which was the most consistent predictor of earlier peaks (Table S4d). Furthermore, this species, which is an indicator of oligotrophy, may have had a competitive advantage over Daphnia earlier in spring under less eutrophic conditions in the last decades.

The peak biomass of Bythotrephes longimanus (Fig. 7j) was clearly higher during the last decade, and the species also appeared to occur earlier in the season (although the long-term trend was not significant). Earlier onset of stratification was the most consistent predictor of earlier peaks for Bythotrephes (Table S4d). This carnivore species is otherwise a summer type which may benefit from warmer water by more rapid population growth. Earlier onset of population growth also means that it may more easily escape predation by fish fry. The higher biomass could also be due to reduced competition from Lepto- 
dora. A similar (but larger) increase in Bythotrephes density and earlier population growth was found in Lago Maggiore (Manca et al. 2007). These changes in phenology and population growth were attributed partly to increasing temperature and partly to a larger refugial volume (below the euphotic zone and above the hypolimnion, where visual predators are avoided) during spring-early summer.

\subsection{Trends in environment and plankton phenology: summary of patterns and processes}

Long-term trends or changes were detected for all the climate-related variables included in this study: lake temperature, stability and stratification duration increased, while the ice cover duration decreased. While the phenology of ice cover was most affected during spring (earlier ice-off), the variables related to lake temperature were more affected (increased) in late summer.

The long-term trends in abundance and seasonal dynamics observed for the phytoplankton classes can be summarised as 3 main types, considering the underlying processes related to both climate and trophic interactions. (1) Earlier growth in spring (Fig. 8a): Chryptophyceae (Fig. 6b), which may benefit from more rapid population growth in a warmer climate. (2) Slower growth in spring (Fig. 8b): Bacillariophyceae and Chlorophyceae (Fig. 6a,f). The most likely explanation is reduced nutrient level (total P). Earlier peaks of certain herbivore zooplankton species (see below) might also contribute to slower growth of these more or less edible phytoplankton taxa. (3) Slower or later decline in summer (Fig. 8c): Chrysophyceae and Dinophyceae (Fig. 6c,e). These classes contain mixotroph species that can benefit from reduced competition of Cyanophyceae, and therefore continue growing later during the season when Cyanophyceae are less abundant. This interaction may be influenced by both nutrient and climatic conditions.

For the 13 zooplankton species comprising $99.9 \%$ of the biomass, 4 species displayed a trend in earlier timing of peak biomass (Table 3). The shift to earlier timing also followed 3 main patterns, which can be explained by different ecological processes. (1) Earlier timing and reduced biomass, caused by earlier decline in population growth (Fig. 8d): B. longispina (Fig. 7b) and Heterocope (Fig. 7h). A likely explanation is reduced phytoplankton biomass as food, at least for the herbivore $B$. longispina. For the omnivore Heterocope, an additional factor may be increased competition by Limnocalanus. (2) Earlier timing and a) Earlier increase

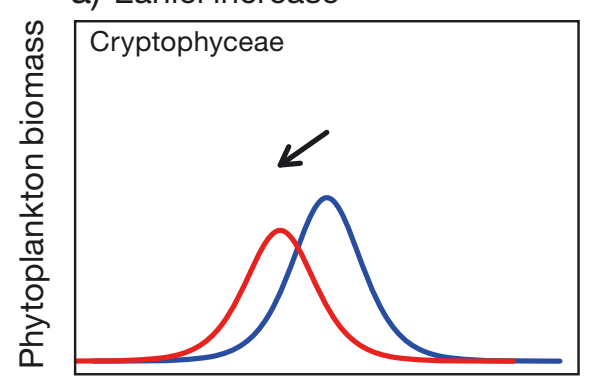

d) Earlier decline

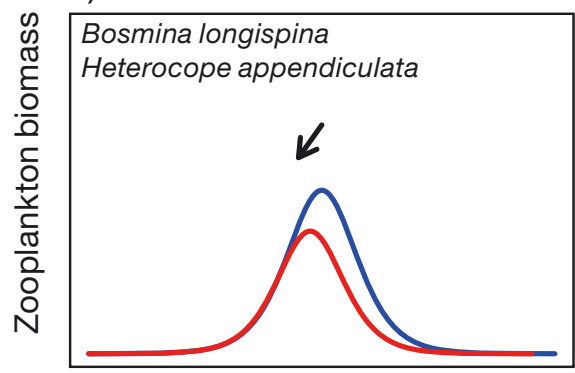

b) Slower increase

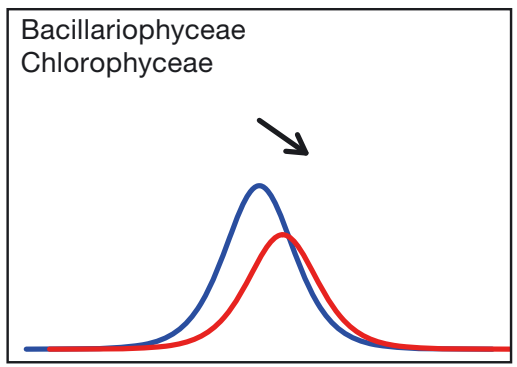

e) Earlierincrease

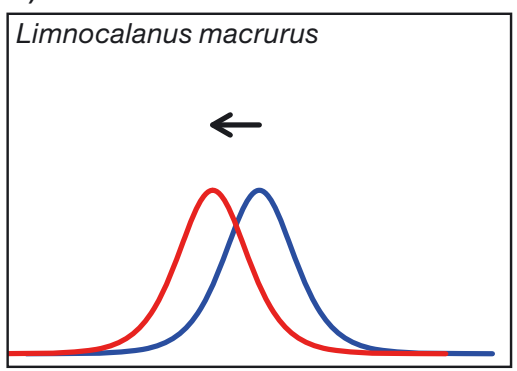

Time of year

\section{C) Slower decline}

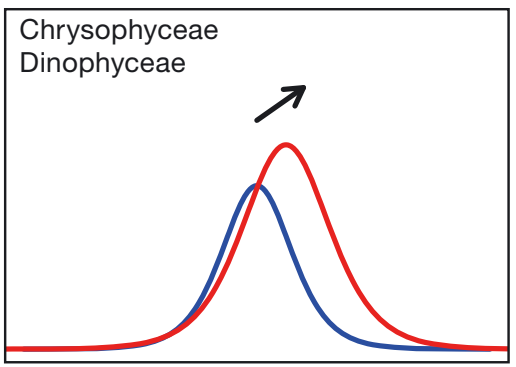

f) Quicker increase

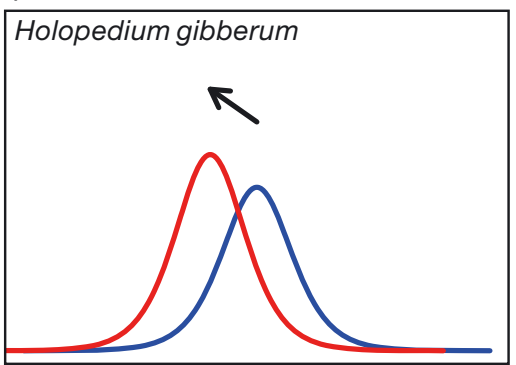

Fig. 8. Main patterns of long-term changes in abundance and seasonal dynamics identified for (a-c) phytoplankton and (d-f) zooplankton. Blue and red curves represent the first and last decade of the $40 \mathrm{yr}$ period (1975-2014), respectively. Arrows indicate the direction of change in abundance and timing (cf. Tables 2 \& 3, column 'Summary') 
unaltered biomass, caused by earlier start of population growth (Fig. 8e): Limnocalanus (Fig. 7a). Earlier warming of the water in spring might give this coldtolerant species an even earlier head start and competitive advantage relative to other species. Other plausible explanations for the earlier start are earlier growth of Cryptophyceae as food for early nauplii, as well as variations in predation pressure. (3) Earlier timing and increased biomass, caused by quicker growth in spring (Fig. 8f): Holopedium (Fig. 7i). This species may get a competitive advantage earlier in spring under less eutrophic conditions. Earlier occurrence of Cryptophyceae might also contribute to more rapid population growth. (The same description applies for Bythotrephes, although the trends were not statistically significant).

The diverging changes in timing of peak biomass described for phytoplankton and zooplankton, and the different causes (nutrients and temperature, respectively), are in accordance with other studies (De Senerpont Domis et al. 2013). For phytoplankton, a cross-lake comparison of shifts in phenology over $58 \mathrm{yr}$ demonstrated that locally variable P levels had a more consistent effect on the timing than temperature (Feuchtmayr et al. 2012). For zooplankton, in contrast, lake comparisons suggest that the timing of biomass peaks is advanced by higher temperature (Straile 2002), although this effect might also be modified by trophic state.

A global meta-analysis of phenological trends show that there have been shifts in the timing of interacting species in recent decades, but there is no consistent trend in the direction of the such changes (Kharouba et al. 2018). A remaining challenge is to predict the direction of changes in phenology of interacting species and the cascading effects for other trophic levels.

\section{CONCLUSIONS AND OUTLOOK}

Identifying the ecological effects of climatic change in lakes that have undergone re-oligotrophication poses methodological challenges. The long-term trends in biomass and seasonal dynamics observed for phytoplankton and zooplankton in Lake Mjøsa were most strongly dominated by a substantial reduction in total $P$ since the 1980s. Nevertheless, the temperature increase recorded for the last 4 decades has also affected the plankton communities. The general longterm trends in phenology have been divergent for phytoplankton (later peaks) vs. zooplankton (earlier peaks). Earlier peaks were nevertheless observed for individual taxa within both groups. The earlier peak of the phytoplankton class Cryptophyceae can be explained by an increase in spring temperatures or other climate-related changes. The earlier onset of population growth of certain zooplankton species can likewise be related to climate change through earlier temperature increase or, more indirectly, by earlier availability of Cryptophyceae as a food source.

Climate-related changes in phytoplankton and zooplankton phenology are also of relevance for the management of fish. The earlier timing of zooplankton dynamics in this lake might have negative consequences for planktivorous fish such as cisco Coregonus albula, for which the timing of larval hatching is coupled with zooplankton dynamics. However, temperature increase might also cause earlier spring floods, which initiates hatching of the fish larvae (Næsje et al. 1986). It has therefore been suggested that climate warming might promote earlier hatching of this planktivorous fish (J. Museth pers. comm.), but data are not yet available to test any such hypothesis. The systematic monitoring of the fish communities which has recently been initiated for this lake (Gjelland et al. 2020) may also enable future investigation of climate-related changes for the higher trophic levels of this ecosystem.

Acknowledgements. This work was funded by the projects SUSTAIN (RCN project no. 244647/E10) and REFRESH (EU FP6 project no. 244121). The lake monitoring data were collected by NIVA on behalf of the Lake Water Mjøsa Association. We thank Tom Andersen (UiO) and Robert Ptacnik (WCL) for contributions to digitalisation of the plankton data, Eiliv Sandlund and Hugh Riley (NIBIO) for providing the ice cover data and Espen Lund (NIVA) for making the map.

\section{LITERATURE CITED}

Adrian R, Wilhelm S, Gerten D (2006) Life-history traits of lake plankton species may govern their phenological response to climate warming. Glob Change Biol 12: 652-661

Adrian R, O'Reilly CM, Zagarese H, Baines SB and others (2009) Lakes as sentinels of climate change. Limnol Oceanogr 54:2283-2297

Anderson MJ (2001) A new method for non-parametric multivariate analysis of variance. Austral Ecol 26:32-46

*Anneville O, Chang CW, Dur G, Souissi S, Rimet F, Hsieh $\mathrm{CH}$ (2019) The paradox of re-oligotrophication: the role of bottom-up versus top-down controls on the phytoplankton community. Oikos 128:1666-1677

Barton K (2020) MuMIn: multi-model inference. R package version 1.43.17. https://CRAN.R-project.org/package= MuMIn

Birk S, Chapman D, Carvalho L, Spears BM and others (2020) Impacts of multiple stressors on freshwater biota across spatial scales and ecosystems. Nat Ecol Evol 4: 1060-1068 
Blenckner T, Adrian R, Livingstone DM, Jennings E and others (2007) Large-scale climatic signatures in lakes across Europe: a meta-analysis. Glob Change Biol 13:1314-1326

Blenckner T, Adrian R, Arvola L, Järvinen M and others (2010) The impact of climate change on lakes in northern Europe. In: George G (ed) The impact of climate change on European lakes. Springer, Berlin, p 339-358

* Carter JL, Schindler DE, Francis TB (2017) Effects of climate change on zooplankton community interactions in an Alaskan lake. Clim Change Responses 4:3

Cushing DH (1990) Plankton production and year-class strength in fish populations: an update of the match/mismatch hypothesis. Adv Mar Biol 26:249-293

* De Senerpont Domis LN, Elser JJ, Gsell AS, Huszar VLM and others (2013) Plankton dynamics under different climatic conditions in space and time. Freshw Biol 58: 463-482

EC (European Commission) (2000) Directive 2000/60/EC of the European Parliament and of the Council of 23 October 2000 establishing a framework for community action in the field of water policy. Off J Eur Comm L 327:1-72

* Edwards M, Richardson AJ (2004) Impact of climate change on marine pelagic phenology and trophic mismatch. Nature 430:881-884

Feuchtmayr H, Thackeray SJ, Jones ID, De Ville M, Fletcher J, James BEN, Kelly J (2012) Spring phytoplankton phenology - Are patterns and drivers of change consistent among lakes in the same climatological region? Freshw Biol 57:331-344

Flaim G, Eccel E, Zeileis A, Toller G, Cerasino L, Obertegger U (2016) Effects of re-oligotrophication and climate change on lake thermal structure. Freshw Biol 61: 1802-1814

Gjelland KØ, Bækkelie KA, Brabrand ^, Kristoffersen R and others (2020) Overvåking av fisk i store innsjøer-FIST 2018. NINA rapport 1749. Norsk institutt for naturforskning, Tromsø

Hering D, Borja A, Carstensen J, Carvalho L and others (2010) The European Water Framework Directive at the age of 10: a critical review of the achievements with recommendations for the future. Sci Total Environ 408: 4007-4019

Hessen DO, Faafeng BA, Andersen T (1995) Competition or niche segregation between Holopedium and Daphnia; empirical light on abiotic key parameters. Hydrobiologia 307:253-261

* Hobæk A, Løvik JE, Rohrlack T, Moe SJ and others (2012) Eutrophication, recovery and temperature in Lake Mjøsa: detecting trends with monitoring data and sediment records. Freshw Biol 57:1998-2014

Holtan H (1990) Lake Mjoesa, recipient and ecosystem. Limnologica 20:285-289

IPCC (2014) Climate Change 2014: synthesis report. Contribution of Working Groups I, II and III to the Fifth Assessment Report of the Intergovernmental Panel on Climate Change. IPCC, Geneva

Jeppesen E, Søndergaard M, Jensen JP, Havens KE and others (2005) Lake responses to reduced nutrient loading an analysis of contemporary long-term data from 35 case studies. Freshw Biol 50:1747-1771

Jeppesen E, Moss B, Bennion H, Carvalho L and others (2010) Interaction of climate change and eutrophication. In: Kernan M, Battarbee RW, Moss B (eds) Climate change impacts on freshwater ecosystems. Wiley-Blackwell, Chichester, p 119-151
Jeppesen E, Nõges P, Davidson TA, Haberman J and others (2011) Zooplankton as indicators in lakes: a scientificbased plea for including zooplankton in the ecological quality assessment of lakes according to the European Water Framework Directive (WFD). Hydrobiologia 676: 279-297

Kagami M, Ibelings BW, de Bruin A, Van Donk E (2005) Vulnerability of Asterionella formosa to Daphnia grazing: impact of a fungal parasite. Verh Int Ver Theor Angew Limnol 29:350-354

Kharouba HM, Wolkovich EM (2020) Disconnects between ecological theory and data in phenological mismatch research. Nat Clim Chang 10:406-415

Kharouba HM, Ehrlen J, Gelman A, Bolmgren K, Allen JM, Travers SE, Wolkovich EM (2018) Global shifts in the phenological synchrony of species interactions over recent decades. Proc Natl Acad Sci USA 115:5211-5216

Killick R, Eckley I (2013) changepoint: an R package for changepoint analysis. R package version 1.1. https:// github.com/rkillick/changepoint/ (accessed 8 April 2020)

Løvik JE, Kjellberg G (2003) Long-term changes of the crustacean zooplankton community in Lake Mjøsa, the largest lake in Norway. J Limnol 62:143-150

K Løvik JE, Moe SJ (2016) Time series of plankton data from Lake Mjøsa, Norway. Freshw Metadata J 18:1-9

Lyche Solheim A, Globevnik L, Austnes K, Kristensen P and others (2019) A new broad typology for rivers and lakes in Europe: development and application for large-scale environmental assessments. Sci Total Environ 697:134043

Lyche Solheim A, Thrane JE, Skjelbred B, Økelsrud A, Håll J, Kile MR (2020) Tiltaksorientert overvåking i vannområde Mjøsa. Årsrapport for 2019. NIVA Rapport No. 7491-2020. Norsk institutt for vannforskning, Oslo

* Manca MM, Portogallo M, Brown ME (2007) Shifts in phenology of Bythotrephes longimanus and its modern success in Lake Maggiore as a result of changes in climate and trophy. J Plankton Res 29:515-525

McLeod AI (2011) Kendall: Kendall rank correlation and Mann-Kendall trend test. R package version 2.2. https:// cran.r-project.org/web/packages/Kendall/Kendall.pdf (accessed 8 April 2020)

Moe SJ, Bennion H, Cid N, Solheim AL and others (2014) Implications of climate change for ecological reference conditions, thresholds and classification systems for European lakes. REFRESH Deliverable 3.15-16. www. refresh.ucl.ac.uk/Deliverable+3.15_abstract

Næsje TF, Jonsson B, Sandlund OT (1986) Drift of cisco and whitefish larvae in a Norwegian river. Trans Am Fish Soc 115:89-93

*Nater CR, Rustadbakken A, Ergon T, Langangen $\varnothing$ and others (2018) Individual heterogeneity and early life conditions shape growth in a freshwater top predator. Ecology 99:1011-1017

Nater CR, Stubberud MW, Langangen $\varnothing$, Rustadbakken A and others (in press) Towards a future without stocking: harvest and river regulation determine long-term population viability of migratory salmonids. Clim Res, doi: $10.3354 / \mathrm{cr} 01644$

Nõges $\mathrm{P}$, Kangur K, Nõges T, Reinart A, Simola H, Viljanen $M$ (2008) Highlights of large lake research and management in Europe. Hydrobiologia 599:259-276

Nõges P, Argillier C, Borja A, Garmendia JM and others (2016) Quantified biotic and abiotic responses to multiple stress in freshwater, marine and ground waters. Sci Total Environ 540:43-52 
O'Reilly CM, Sharma S, Gray DK, Hampton SE and others (2015) Rapid and highly variable warming of lake surface waters around the globe. Geophys Res Lett 42: 10773-10781

Oksanen J, Blanchet FG, Friendly M, Kindt R and others (2019) vegan: community ecology package. R package version 2.5-6. https://CRAN.R-project.org/package=vegan

Paerl HW, Huisman J (2008) Blooms like it hot. Science 320: 57-58

Pawlowski MB, Branstrator DK, Hrabik TR (2018) Major shift in the phenology of crustacean biomass in western Lake Superior associated with temperature anomaly. J Gt Lakes Res 44:788-797

Pomati F, Matthews B, Jokela J, Schildknecht A, Ibelings BW (2012) Effects of re-oligotrophication and climate warming on plankton richness and community stability in a deep mesotrophic lake. Oikos 121:1317-1327

Ptacnik R, Solimini A, Brettum P (2009) Performance of a new phytoplankton composition metric along a eutrophication gradient in Nordic lakes. Hydrobiologia 633: 75-82

R Core Team (2020) R: a language and environment for statistical computing. R Foundation for Statistical Computing, Vienna. https://www.R-project.org/

Shimoda Y, Azim ME, Perhar G, Ramin M and others (2011) Our current understanding of lake ecosystem response to climate change: What have we really learned from the north temperate deep lakes? J Gt Lakes Res 37:173-193

Smoliński S, Glazaczow A (2019) Cascading effects of temperature alterations on trophic ecology of European grayling (Thymallus thymallus). Sci Rep 9:18358

Straile D (2002) North Atlantic Oscillation synchronizes food-web interactions in central European lakes. Proc R

Editorial responsibility: Christian Damgaard (Guest Editor), Silkeborg, Denmark

Reviewed by: 3 anonymous referees
Soc B 269:391-395

* Thackeray SJ, Henrys PA, Hemming D, Bell JR and others (2016) Phenological sensitivity to climate across taxa and trophic levels. Nature 535:241-245

Vadadi-Fülöp C, Hufnagel L (2014) Climate change and plankton phenology in freshwater: current trends and future commitments. J Limnol 73:1-16

*Vadadi-Fülöp C, Sipkay C, Mészáros G, Hufnagel L (2012) Climate change and freshwater zooplankton: What does it boil down to? Aquat Ecol 46:501-519

Verbesselt J, Hyndman R, Zeileis A, Culvenor D (2010) Phenological change detection while accounting for abrupt and gradual trends in satellite image time series. Remote Sens Environ 114:2970-2980

*Weyhenmeyer GA (2001) Warmer winters: Are planktonic algal populations in Sweden's largest lakes affected? Ambio 30:565-571

Winder M, Schindler DE (2004) Climate change uncouples trophic interactions in an aquatic ecosystem. Ecology 85: 2100-2106

*Winder M, Schindler DE, Essington TE, Litt AH (2009) Disrupted seasonal clockwork in the population dynamics of a freshwater copepod by climate warming. Limnol Oceanogr 54:2493-2505

Winslow L, Read J, Woolway R, Brentrup J, Zwart J (2013) rLakeAnalyzer: package for the analysis of lake physics. $\mathrm{R}$ package version 1.0. https://cran.r-project.org/web/ packages/rLakeAnalyzer/rLakeAnalyzer.pdf (accessed 8 April 2020)

Winslow L, Read J, Woolway R, Brentrup J and others (2019) rLakeAnalyzer: Lake physics tools. R package version 1.11.4.1. https://CRAN.R-project.org/package= rLakeAnalyzer

Submitted: September 2, 2020

Accepted: April 15, 2021

Proofs received from author(s): June 29, 2021 